\title{
Medidas financieras en el entorno de los negocios, para minimizar los efectos de la pandemia COVID-19
}

\author{
Financial measures in the business environment, to minimize the effects of \\ the COVID-19 pandemic
}

Edison Becerra Molina. ${ }^{1}$, Gina Cuadrado Sánchez. ${ }^{2}$ \& María Eliza Flores Flores. ${ }^{3}$

\begin{abstract}
DOI: https://doi.org/10.33262/concienciadigital.v4i3.1800

Introduction. The financial field is the main means of reference for topics related to the economy, constituting a fundamental basis in business by recognizing the value of the information regarding the obtaining and efficient use of money over time. Objective. To analyze the role of the financial system in the Coronavirus crisis Methodology. The research design was based on the positivist research paradigm, type of research based on a non-experimental and transectional field design with documentary support, descriptive research level, the population was 77,289 and the sample 471, the questionnaire instrument was used, the same was validated through the judgment of experts with experience in the financial, accounting and methodology areas, qualifying validity, clarity, coherence and relevance. Results. Regarding the importance of the deferral of debt payments that affected MSMEs, $50.53 \%$ stated that this measure ordered by the Monetary Policy and Regulation Board was important, while $25.69 \%$ stated that it was very important, and if we combine these trends we have $76.22 \%$, which means a financial relief to the sudden cut in their income and therefore in their ability to meet their payments, it was necessary then to opt for the deferral, $17.83 \%$ remained neutral to the

\footnotetext{
1 Universidad Católica de Cuenca, Carrera de Contabilidad y auditoría, provincia Azuay, código, jbecerram@ucacue.edu.ec, Orcid.Org ID: 0000-0002-6397-9493

2 Universidad Católica de Cuenca, Carrera de Contabilidad y auditoría, provincia Azuay, código, gcuadrado@ucacue.edu.ec, Orcid.Org ID: 0000-0002-4259-4906

3 Universidad Católica de Cuenca, Carrera de Contabilidad y auditoría, provincia Azuay, código, mefloresf@ucacue.edu.ec Orcid.Org ID: 0000-0002-7348-4523
} 
deferral of payments for loans granted by financial institutions, $5.10 \%$ stated that it was not very important, while $0.85 \%$ maintained that it was not important, since they did not consider this benefit under the new conditions because in the end they would end up paying the capital and interest over a longer period of time. Conclusion. The banking sector has to rise to the occasion, guaranteeing the liquidity and financing that companies need, hence the importance of the financial sector to support the country's economy.

Keywords: COVID-19, Economics, MSMEs, Financial Institutions, Financial Policy.

\section{Resumen}

Introducción. El ámbito financiero es el principal medio de referencia para los temas vinculados a la economía, constituyendo una base fundamental en los negocios al reconocer el valor de la información, referente a la obtención y uso eficaz del dinero a través del tiempo. Objetivo. Analizar el papel del sistema financiero en la crisis del Coronavirus Metodología. El diseño de la investigación partió del paradigma de investigación positivista, tipo de investigación basada en un diseño de campo no experimental y transeccional con apoyo documental, nivel de investigación descriptiva, la población fue 77.289 y la muestra 471, se utilizó el instrumento del cuestionario, el mismo fue validado mediante juicio de expertos con experiencia en el área financiera, contabilidad y metodología, calificando validez, claridad, coherencia, y relevancia. Resultados. con respecto a la importancia del diferimiento de pagos de deudas que incidieron en las Mipymes, 50,53\% sostuvieron que fue importante esta medida dispuesta por la Junta Política y Regulación Monetaria, en tanto que 25,69\% afirman que fue muy importante, uniendo estas tendencias tenemos 76,22\%, lo que supone un alivio financiero al corte súbito en sus ingresos y por tanto en su capacidad para hacer frente a sus pagos, fue necesario entonces optar por el diferimiento, que permitió apaciguar el impacto en los negocios que no tuvieron ingresos seguros, $17,83 \%$ se mantuvo neutral ante el diferimiento de pagos por créditos otorgados por las Instituciones Financieras, 5,10\% manifestaron que es poco importante, mientras que $0,85 \%$ sostuvieron que no es importante, toda vez que no consideraron este beneficio bajo nuevas condiciones porque al final terminaran pagado el capital y sus intereses en un tiempo más prolongado. Conclusión. La banca tiene que estar a la altura de las circunstancias, garantizando la liquidez y la financiación que necesitan las empresas, de allí la importancia que tiene el sector financiero para apoyar a la economía del país.

Palabras claves: COVID-19, Economía, Mipymes, Instituciones Financieras, Política financiera.

\section{Introducción}

El COVID-19, ha tenido un impacto devastador en Ecuador, la pandemia y la fuerte caída de los precios del petróleo han planteado un gran desafío para la economía ecuatoriana y han generado significativas limitaciones financieras, de allí que los gobiernos nacionales tomaron medidas decisivas para contener la propagación del virus y mitigar el impacto socioeconómico de la crisis de salud en los hogares y las empresas, al tiempo que 
priorizaron financiar los sistemas de asistencia social y de salud, así como catalizaron el financiamiento desde instituciones financieras multilaterales.

El sistema financiero a nivel nacional y mundial, lleva de distintas maneras la aplicación y tratamiento de sus cuentas, debido a que conllevan a desarrollar el manejo de sus ingresos y egresos destinados netamente a actividades que estén en la fase de viabilidad, por el cual se deberá mantener un plan financiero que incluya las particularidades de cada actividad económica y permita la sostenibilidad de las mismas.

La Junta de Política y Regulación Monetaria y Financiera forma parte de la Función Ejecutiva como responsable de la formulación de las políticas públicas y la regulación y supervisión monetaria, crediticia, cambiaria, financiera de seguros y valores, la misma está conformada con plenos derechos por los titulares de los ministerios de Estado responsables de la política económica, de la producción, de las finanzas públicas, el titular de la planificación del Estado y un delegado del Presidente de la República. Participarán en las deliberaciones de la Junta, con voz, pero sin voto, el Superintendente de Bancos, el Superintendente de Compañías, Valores y Seguros, el Superintendente de Economía Popular y Solidaria, el Gerente General del Banco Central del Ecuador, y el Presidente del Directorio de la Corporación de Seguro de Depósitos, Fondo de Liquidez y Fondo de Seguros Privados.

Por su parte, el Banco Central del Ecuador (2021), cumple su rol de facilitador y regulador del sistema de pagos: recibe depósitos de instituciones públicas, como el Instituto Ecuatoriano de Seguridad Social, los municipios, entre otros y también funge como custodio de los fondos públicos, hasta que esas instituciones decidan transferirlos para cumplir con sus diferentes obligaciones, no funciona como un banco comercial que toma dinero de los ciudadanos y concede préstamos, además salvaguarda un porcentaje de los depósitos que hacen los ciudadanos en el sistema financiero privado, que se lo conoce con el nombre de encaje bancario, y determina que, por ley, los bancos y cooperativas necesariamente deben mantener un porcentaje del dinero que le confían sus ahorristas en el Banco Central). Es una reserva de liquidez y, en el caso de que haya una crisis o corrida de depósitos, será el Banco Central del Ecuador, quien deberá entregar esos dineros al banco o cooperativa que, a su vez, deberá devolver a sus depositantes.

Actualmente se exige el 5\% a los siete bancos más grandes, 4\% a los medianos y pequeños, y $3 \%$ a ciertas cooperativas de ahorro y crédito, las más grandes. El proyecto mantendrá los porcentajes, además exigirá a las cooperativas más pequeñas, que salvaguarden sus depósitos en el BCE, con el 1\% y el 2\%, así mismo el BCE emite informes técnicos sobre el Presupuesto General del Estado, y el endeudamiento público para establecer una opinión independiente del ejecutivo sobre el sustento de las cifras y el manejo económico.

Por otro lado, tanto los préstamos como los créditos están pensados para resolver problemas de financiación de las empresas, se considera a un préstamo como una operación financiera que lleva a cabo una institución financiera que le entrega a una 
persona u empresa, en calidad de prestatario una cantidad de dinero que este último requiera, como consecuencia de ello se tendrá que devolver dicha cantidad más los correspondientes intereses pactados en un plazo determinado.

De allí que es importante que tanto las micro, pequeñas y medianas empresas, desplieguen esfuerzos para atenuar la emergencia sanitaria de COVID- 19 y sus impactos en la economía, por consiguiente, las Mipymes tienen la imperiosa necesidad de financiamiento, como un mecanismo para cubrir sus obligaciones en materia de producción, obligaciones con sus empleados, proveedores, la administración tributaria, la seguridad social entre otros, su objetivo es mantener un nivel de liquidez con el cual puedan pagar sus obligaciones y llevar a cabo sus proyectos, adquirir bienes o servicios, cubrir sus costos y gastos, es decir cumplan con los compromisos adquiridos, gracias a ello, las empresas pueden acceder a los recursos para llevar a cabo sus actividades sin contratiempos en el corto plazo, asegurando una salud financiera que les permita mantenerse en el mercado, planificar su futuro y expandirse.

Este trabajo es parte del proyecto de investigación denominado "La importancia de la información contable y financiera ante la incertidumbre del COVID-19 en las Mipymes en el entorno de los negocios en la región 6", el mismo que se justifica porque contribuye desde una perspectiva teórica académica a dar salida a los problemas de liquidez de las micro, pequeñas y medianas empresas, debido a que el financiamiento es un motor importante para el desarrollo de la economía, la creación, desarrollo y sostenibilidad de las empresas.

\section{Metodología}

En la parte metodológica de la investigación, se utilizó el paradigma de investigación positivista, tipo de investigación diseño de campo no experimental y transeccional o transversal con apoyo documental. Según, Arias (2016) la investigación de campo o diseño de campo consiste en: La recolección de datos directamente de los sujetos investigados, o de la realidad donde ocurren los hechos, (datos primarios), sin manipular o controlar variable alguna, es decir el investigador obtiene la información, pero no altera las condiciones existentes. De allí su carácter de investigación no experimental (p. 25).

El nivel de investigación fue la investigación descriptiva, en este sentido, es apropiado citar a Yuni y Urbano, (2006), quienes afirman que la investigación de tipo descriptiva tiene como objetivo: Llegar a conocer las situaciones, costumbres y actitudes predominantes a través de la descripción exacta de las actividades, objetos, procesos y personas. Su meta no se limita a la recolección de datos, sino a la predicción e identificación de las relaciones que existen entre dos o más variables. Los investigadores no son meros tabuladores, sino que recogen los datos sobre la base de una hipótesis o teoría, exponen y resumen la información de manera cuidadosa y luego analizan minuciosamente los resultados, a fin de extraer generalizaciones significativas que contribuyan al conocimiento (p. 33). 
Se corresponde, por tanto, con el nivel descriptivo en función del objetivo general planteado, la población estuvo estructurada por tres sectores escogidos de microempresas, considerando la base del catastro del SRI del 2021, así Azuay con 45.814, Cañar 10.497 y Morona Santiago 11.300, total 67.611 microempresas de la Zona 6 del Austro, de las cuales son empresas registradas en la Superintendencia de Compañías por el año 2021 en Azuay 8.843, Cañar 494 y Morona Santiago 341, total 9.678, dando un gran total de 77.289, se determinó el tamaño de la muestra con un 4,50\% de error, determinándose por tanto la muestra $n=471$, la validez de contenido fue realizado mediante el juicio de tres expertos con experiencia en el área de financiera, contabilidad y metodología.

Por su parte, fue importante analizar en primer lugar, la pertinencia del coeficiente de consistencia interna de Cronbach, el misma que trata sobre el grado en que los ítems miden la homogeneidad. Para determinar la confiabilidad del cuestionario elaborado, se procedió aplicar una prueba piloto a 30 empresas, que no forman parte de la muestra, todos ellos con características similares a los sujetos de este estudio, administrando una escala, de 7 ítems, a una muestra de $\mathrm{n}=30$. De acuerdo con los resultados anteriores, se concluyó que la escala tiene una confiabilidad de consistencia interna muy alta, suficientemente alta como para ser considerada fiable. En conclusión, la confiabilidad del instrumento fue de 0,9 muy alta, así mismo, fue sustancial la utilización de la herramienta estadística para el desarrollo de la investigación, recurriéndose a la estadística descriptiva, lo que permitió la recolección, organización, análisis y presentación de datos con el apoyo de cuadros, tablas, figuras y los resultados obtenidos de la aplicación de los cuestionarios en relación con los objetivos planteados del presente estudio, recurriéndose a la estadística descriptiva mediante el software libre SPSS, versión 26.

El análisis de los datos es una parte esencial de toda investigación, en tal sentido, Hernández, Fernández, y Baptista (2016), sostienen que "el procedimiento que se sigue para analizar los datos consiste en: Una vez que los datos se han codificado, transferido a una matriz, guardado en un archivo y "limpiado" los errores, el investigador procede a analizarlos utilizando un programa computacional” (p. 272). En base a lo cual se procedió a inspeccionar, limpiar y transformar datos con el objetivo de resaltar información útil, lo que sugiere conclusiones, y apoyo a la toma de decisiones.

Posterior a los procedimientos que condujeron a reunir datos con el propósito específico de estructurar un análisis de la normativa financiera, se procedió a revisar los datos o respuestas obtenidas mediante Google forms. Las respuestas a los cuestionarios se recopilan de forma automática y ordenada en formularios, con figuras y datos de las respuestas en tiempo real, que fueron procesados, analizados e interpretados, considerando el uso de la triangulación, validez, confiabilidad y contrastación de los instrumentos.

\section{Fundamentación Teórica}

El marco teórico referencial comprende aspectos teóricos, conceptuales, legales, situacionales de la realidad que forman parte de la presente investigación, garantizando de esta manera la integración e interrelación de la teoría con la metodología y objetivos 
de investigación, por tanto constituye la revisión de otras investigaciones que sirvieron de antecedente al presente estudio, ante la incertidumbre del COVID-19 en el contexto de las Mipymes, en el entorno de los negocios en la región 6, es oportuno indicar que el campo de las finanzas es amplio y dinámico, concierne todo el manejo que realizan las empresas en torno al uso adecuado del dinero, como la contratación de personal, la construcción de una la infraestructura, hasta el lanzamiento de nuevas campañas de publicidad, por ello las finanzas se definen como el arte y la ciencia de administrar el dinero.

Según Tamayo (2020), Decano de la Facultad de Ciencias Financieras y Contables de la Institución Universitaria ESCOLME, el estudio del área financiera implica considerar cuestionamientos con respecto a la administración financiera, por ejemplo, ¿qué son las finanzas empresariales?, ¿qué papel juegan las finanzas en el alcance del éxito empresarial?, ¿quién es el encargado del manejo financiero dentro de una empresa?, ¿cuáles son las funciones del administrador financiero?, ¿qué relación tienen las finanzas con el conjunto de actividades que se realizan en una empresa?, ¿cómo incide el entorno empresarial en el desarrollo de las funciones del administrador financiero?, entre otras.

La operación de una empresa involucra llevar a cabo una serie de actividades o funciones que en términos generales se pueden agrupar en cuatro categorías: Mercadeo, producción, talento humano y finanzas, todas ellas integradas e interdependientes y en pro de lograr maximizar el valor de la compañía. La gestión financiera implica conocer estas interrelaciones y la forma como inciden en el acontecer de la empresa, por ello que la implementación de estrategias exige que se deban comprometer fondos de la empresa en tanto que todas las áreas funcionales son generadoras de proyectos y demandadoras de fondos.

Según, Alicia Bárcena, Secretaria de la Comisión Económica para América Latina y el Caribe -CEPAL (2021), pasará para la historia la crisis causada por el COVID-19, como una de las peores que el mundo ha vivido. Advirtió que es un riesgo global que impactará a una economía mundial ya debilitada, además incidirá tanto en la oferta como la demanda por la interrupción de las cadenas de producción afectando el comercio mundial, dando como resultado la pérdida de ingresos y ganancias ocasionando un mayor desempleo y dificultades para cubrir deudas.

Bacerna (2021) sostiene que en la región latinoamericana se vio afectada negativamente ya que su tasa estimada creció apenas un $0,1 \%$ en 2019 y los pronósticos realizados preveían un crecimiento de $1,3 \%$, pero luego de ser revisadas las proyecciones tuvieron una baja significativa por el actual escenario, se estima una contracción del -1,8\% del producto interno bruto regional, dando como consecuencia que el desempleo se incremente en diez puntos porcentuales en la región, incrementando a 220 millones el número de personas pobres, además podría aumentar a 67,4 a 90 millones de personas en pobreza extrema: Uno de los canales que más afectó a la región es la disminución de actividad económica con principales socios comerciales de bienes como China, que es el 
destino de exportaciones de varias economías latinoamericanas, se estima que las exportaciones a este destino podrían caer hasta $10,7 \%$ en valor.

Por otra parte, también se prevé que un segundo canal proveniente del turismo tendrá severos impactos afectando más a países del Caribe, debido a la prohibición de viajes por causa de la pandemia; otro canal que afectaría a la región de América Latina y el Caribe seria la caída de los precios de productos básicos, en especial para países que exportan materia prima en América del Sur. Además, también será afectado es el índice de riesgo de los inversionistas sumado el empeoramiento de las condiciones financieras globales.

El papel del Fondo Monetario Internacional - FMI, en América Latina durante la crisis desencadenada por la COVID-19 está suponiendo un duro golpe para los países de América Latina. Al alto número de víctimas registrado a consecuencia de la pandemia se suma un fuerte impacto sobre el tejido económico y social. El estancamiento del crecimiento de la región en los últimos años, así como las características socioeconómicas de muchos de estos países, con altos niveles de desigualdad e importantes bolsas de pobreza (exacerbados por la pandemia), ponen en riesgo los éxitos cosechados en la etapa previa. En este contexto, este artículo repasa la actividad financiera desplegada por el Fondo Monetario Internacional y su compromiso en la región y se analizan las posibilidades que ofrece una probable nueva asignación general de derechos especiales de giro por parte del FMI para apoyar a países de renta media con mucha población por debajo de la línea de la pobreza (Casero, Crespo, Mateo, \& Vidal, 2020).

Del mismo modo, instituciones financieras internacionales afirman que un gran número de actores políticos abogan tanto a nivel nacional como internacional por políticas económicas y sociales para afrontar la crisis sanitaria del COVID-19 y la recesión económica a la que ha sumido al mundo, que coadyuven al fortalecimiento inmediato de los sistemas de protección social y de los sistemas de salud.

Al respecto el Fondo Monetario Internacional (FMI), apartándose de sus clásicas recetas promercado y de estricta disciplina fiscal, sostiene que deben implementarse medidas para proteger las vidas de las personas y contribuir a los sustentos de los hogares, incluyendo la asistencia a trabajadores, desocupados y empresas para restaurar lo antes posible el comercio y los flujos financieros una vez que comience la recuperación económica, sostienen que los hogares que pierdan sus ingresos, por las medidas del confinamiento necesitarán apoyo gubernamental, y que las prestaciones por desempleo deben ampliarse y extenderse, de allí se hace necesario apoyar los esfuerzos de los países para calibrar sus políticas sociales para reducir la desigualdad, proteger a las personas vulnerables y promover el acceso de oportunidades para todos, dejando de lado las políticas androcéntricas en América Latina todos (Boholasvsky, 2020).

Así mismo, para el Ecuador la crisis que está viviendo por la pandemia supone un desafío, para mantener el bienestar presente y futuro de los ecuatorianos, el impacto causado por la crisis del COVID-19 afecto económica y socialmente al Ecuador en su lucha por alcanzar un desarrollo inclusivo y sostenible, ante estos problemas es fundamental brindar soluciones a la crisis a través de políticas que ayuden a superar el impacto causado desde 
su fase inicial hasta la reactivación y recuperación. La economía ecuatoriana tendrá una contracción, la mayor de su historia provocada por la pandemia, con una caída del PIB de entre un 7,3\% y un 9,6\% según las estimaciones del Banco Central del Ecuador, o según el FMI una contracción del 10,9\% (Centro de Desarrollo de la OCDE, 2020).

Todo esto sumado a la crisis provocada por la reducción en la recaudación tributaria, el decrecimiento de ingresos petroleros por la caída del precio del crudo en el mercado internacional, ocasionando una erosión en las cuentas públicas. Además, las medidas que se adoptaron para dar respuesta a la emergencia sanitaria, para mitigar el impacto socioeconómico, solicita un desplazamiento importante de recursos financieros.

Los analistas económicos manifiestan que para cubrir las necesidades brutas de financiamiento que Ecuador enfrenta seria cerca de unos USD 13.400 millones, con una brecha de financiamiento aun sin cubrir de al menos USD 2000 millones según le FMI. Entre las principales opciones tomadas por el país han sido: 1) financiamiento externo adicional por parte de organismos multilaterales o en forma de préstamos bilaterales oficiales; 2) reestructuración de la deuda externa, para reperfilar los pagos, reducir el capital adeudado, aliviar las necesidades financieras de corto plazo y extender en el tiempo los compromisos de pago; 3) reordenar los recursos disponibles en el plano doméstico, reorientando el gasto hacia acciones prioritarias, reduciendo gastos superfulos, aprovechando los recursos existentes con un uso más eficiente, y movilizando recursos adicionales para generar nuevos ingresos, por ello que para el Ecuador el objetivo fundamental es guiar acciones para atender las necesidades más urgentes y precautelar a quienes estén vulnerables al impacto de la crisis teniendo en cuenta que se debe proteger la estabilidad económica, evitando despilfarrar los recursos y agravar la crisis (OCDE, 2020).

En el Ecuador las micro, pequeñas y medianas empresas existentes son las responsables del crecimiento de la producción, la generación de plazas de empleo, la innovación y el dinamismo productivo del país, por lo que el INEN ha creado "Mi primer Certificado INEN", cuya vigencia es de 3 años y puede ser renovado por un periodo igual al establecido, con un informe favorable de la Dirección de Validación y Certificación, cabe destacar que las Mipymes se encuentran inmersas en todas las actividades productivas de la economía, tales como el comercio al por mayor y al por menor; agricultura, silvicultura y pesca; industrias manufactureras; construcción; transporte, almacenamiento y comunicaciones; bienes inmuebles, entre otros, según datos del 2019 del Instituto Nacional de Estadísticas y Censos (INEC), está constituido por 882.766 empresas, de las cuales las Mipymes representan aproximadamente el $90.89 \%$ del total de empresas registradas. En este contexto el Servicio Ecuatoriano de Normalización -INEN, vio la necesidad de potenciar esta actividad, por lo que invita a las Mipymes y las organizaciones de Economía Popular y Solidaria a obtener dicha certificación cumpliendo con requisitos legales, de gestión financiera, gestión de recursos humanos, servicio al cliente, gestión de compras, control de la producción, calidad del producto, conservación y entrega del producto; además de innovación y emprendimiento (INEN, 2020). 
Según el artículo 3, párrafo 5 de la Constitución de la República del Ecuador (2008), la responsabilidad principal del país es la planificación del desarrollo nacional, la erradicación de la pobreza, desarrollo sostenible y; una justa redistribución de recursos y riqueza para acceder al buen vivir.

A tono con lo que la Constitución estipula, es importante señalar la necesidad de propender a una mejor distribución de la riqueza enmarcada en los Objetivos del Plan Nacional del Buen Vivir Toda una Vida PNDTV (2017-2021), al Eje 2 "Economía al Servicio de la Sociedad", que toma como punto de partida la premisa de que la economía debe estar al servicio de la sociedad.

Es así que nuestro sistema económico, por definición constitucional, se basa en la economía social y solidaria; dentro de este sistema económico interactúan los subsistemas de la economía pública, privada, popular y solidaria. No se puede entender la economía sin abarcar las relaciones entre los actores económicos de estos subsistemas, que son de gran importancia y requieren incentivos, regulaciones y políticas que promuevan la productividad y la competitividad.Entre los Objetivos Nacionales de Desarrollo para alcanzar el Buen Vivir que guarda relación con el ámbito financiero, es el Objetivo $\mathrm{N}^{\circ} 5$, "Impulsar la productividad y competitividad para el crecimiento económico sostenible, de manera redistributiva y solidaria".

De acuerdo con la Ley Orgánica de Apoyo Humanitario (2020) para combatir la crisis sanitaria derivada del COVID-19, fue institucionalizada y aprobada a través de la Asamblea Nacional, como medio para sobrellevar la crisis sanitaria existente y por la que el mundo entero atraviesa, esta ley garantiza y promueve en cierto grado el derecho de los trabajadores y empleadores, además se trata de sostener el equilibrio económico nacional a través de estrategias entre las cuales se destacan: el diferimiento de las cuotas de los préstamos, obligaciones tributarias, cobro de servicios básicos, pago de pensiones, como la prohibición de despido ineficaz, intempestivo entre otros.

De la misma manera, la Ley Orgánica de apoyo humanitario (2020), para combatir la crisis sanitaria derivada del COVID-19, tiene por objeto establecer medidas de apoyo humanitario, necesarias para enfrentar las consecuencias derivadas de la crisis sanitaria ocasionada por el COVID-19, a través de acciones tendientes a mitigar sus efectos adversos dentro del territorio ecuatoriano; que permitan fomentar la reactivación económica y productiva del Ecuador, con especial énfasis en el ser humano, la contención y reactivación de las economías familiares, empresariales, la popular y solidaria, y en el mantenimiento de las condiciones de empleo (p. 6).

El Banco Central del Ecuador y las Superintendencias de Bancos y de Economía Popular y Solidaria establecieron los procedimientos y mecanismos para que las entidades del sistema financiero nacional reporten la información de los segmentos de crédito definidos en la resolución No. 059-2015-F de fecha 16 de abril del 2015. Se aplicarán únicamente respecto de las operaciones de crédito desembolsadas o compradas a partir de la fecha de las resoluciones de los organismos de control del sistema financiero, mediante las cuales, en el ámbito de su competencia, expidan los catálogos de cuenta, los procedimientos y 
los reportes de información necesarios para su implementación. Los créditos comerciales prioritarios, corporativo, para personas naturales obligadas a llevar contabilidad, personas jurídicas que registren ventas anuales superiores a USD 5,000,000.00, los créditos a nivel empresarial orientados a personas naturales obligadas a llevar contabilidad, personas jurídicas que registren ventas anuales superiores a USD 1.000.000.00 y hasta USD 5.000,000.00; el crédito Pymes destinado a personas naturales obligadas a llevar contabilidad y personas jurídicas cuyas ventas anuales sean superiores a USD 100.000.00 y hasta USD 1.000.000.00. Para el caso de los Microcréditos, los solicitantes de crédito cuyo saldo adeudado en microcréditos a la entidad del Sistema Financiero, incluyendo el monto de la operación solicitada sea: Minorista, Menor o igual a USD 1.000.00, Acumulación simple, superior a USD 1.000.00 y hasta USD 10.000.00, Acumulación ampliada, superior a USD 10.000.00.

Del mismo modo, las tasas de interés son la pesadilla de todo deudor; sea este un consumidor con su tarjeta de crédito, un emprendedor que requiere capital de trabajo, una empresa con planes de expansión, o un gobierno que necesita recursos para enfrentar una crisis. Por consiguiente, estamos hablando del precio del dinero, la utilidad del acreedor, el costo financiero de la operación crediticia, o una cobertura monetaria para preservar el poder adquisitivo del dinero en el tiempo; constituye, con las garantías o colateral, el principal determinante del acceso y demanda del mercado de crédito.

En lo que respecta, al marco del acuerdo con el Fondo Monetario internacional -FMI (2019), y dentro del Memorando de Políticas Económicas y Financieras, se estableció como uno de sus compromisos de política pública reforzar la resiliencia del sistema financiero a través de la profundización en los niveles de intermediación financiera, apuntalando la revisión de políticas de tasas de interés, que ayuden a promover la inclusión financiera. Intuitivamente, este compromiso supondría la revisión de la actual política que pone límites máximos a la fijación de tasas por tipo de crédito.

\section{Resultados}

Para el procesamiento y análisis de la información proporcionada por las micro, pequeñas y medianas empresas, en el presente trabajo de investigación, fue necesario acudir a la técnica de la encuesta y el instrumento del cuestionario, en un total de 30 ítems, seleccionando únicamente cinco por ser los más transcendentales.

Figura 1. Capacidad de operaciones por la presencia del COVID 19.

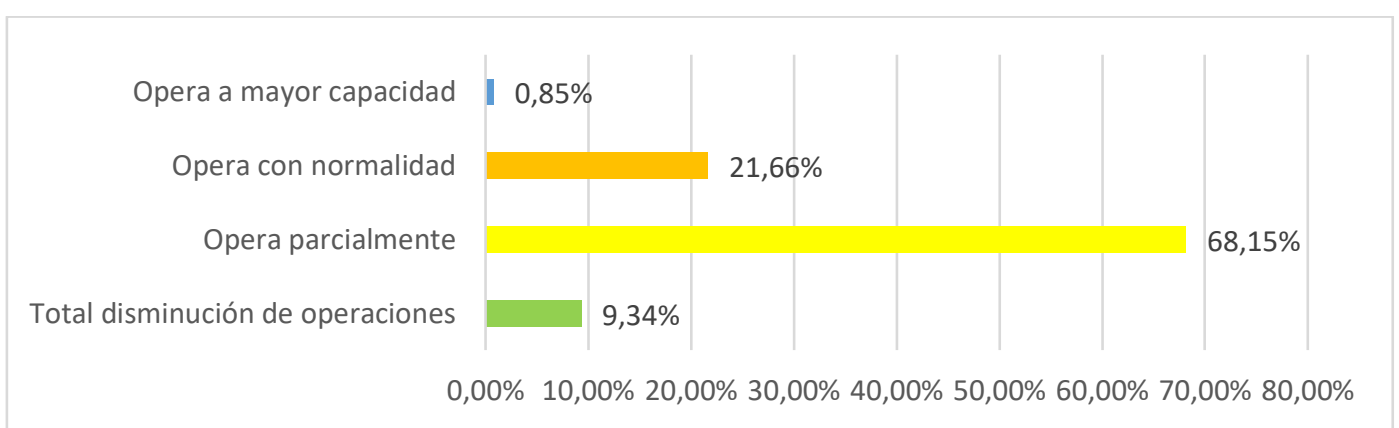

Fuente: Elaboración propia (2021). 
El análisis de la figura $\mathrm{N}^{\circ} 1$ muestra la capacidad de operaciones ante la presencia del COVID 19, los ejecutivos empresariales sostienen que operan parcialmente el $68.15 \%$, como consecuencia de la caída en los ingresos, por la disminución de las ventas, por otra parte operan con normalidad un $21.66 \%$, la nueva realidad económica y social que se vive hoy presenta una disminución de operaciones en $9.34 \%$, debido a que el perfil del consumidor ha cambiado para siempre, tras la crisis, la incertidumbre de la "nueva normalidad" obliga a las empresas y marcas a adaptarse con rapidez.

De acuerdo con el análisis realizado a algunas empresas reguladas por la Superintendencia de Compañías, Valores y Seguros, se presentan resultados, considerando la información financiera con corte a 31 de diciembre de 2020. El análisis fue medido por ingresos operacionales y reportado por las sociedades que entregaron información financiera, esto nos permite darle una mirada más amplia al tejido empresarial del país, en un año especialmente difícil como lo fue el 2020 por el impacto de la pandemia, en el que se evidenció pérdidas, al respecto tan solo el $0.85 \%$ de las empresas objeto de análisis se encuentra operando a mayor capacidad, en este grupo estarían especialmente los sectores que tienen como actividad la industria farmacéutica, sectores de atención de salud humana y asistencia social; y, aquellas empresas dedicadas a la venta de alimentos por ejemplo el sector de supermercados, y empresas del sector industrial y comercial dedicados a los ámbitos antes mencionados, fueron las empresa con más ventas generadas durante el año de la pandemia, según el Ranking Empresarial elaborado por la Superintendencia de Compañías. Por consiguiente, las empresas deberán establecer los protocolos internos necesarios que garanticen la continuidad de sus operaciones y les permitan cumplir en la medida de lo posible, con sus obligaciones laborales, fiscales y legales en general, para no afectar sus operaciones futuras, además de garantizar los flujos de liquidez, conservar las plazas de empleo y la actividad productiva con el fin de reactivar el aparato productivo ante la presencia del COVID-19.

Figura 2. Rango de ventas aproximado en el año 2020

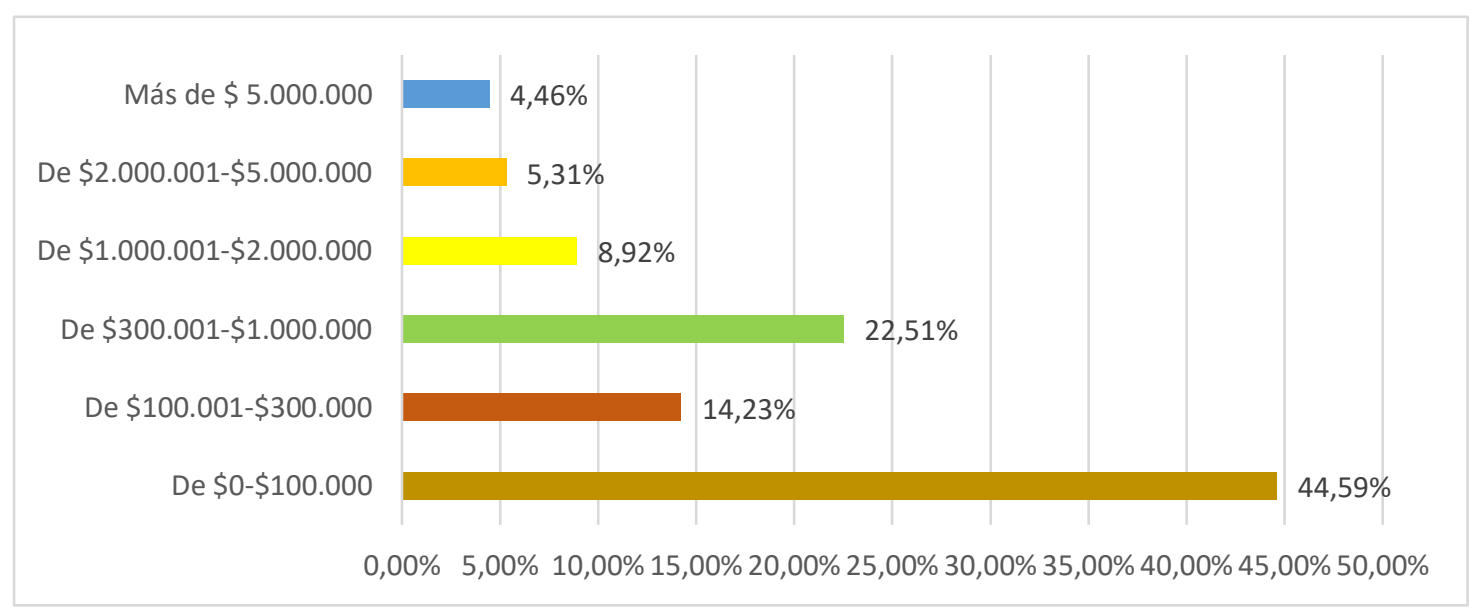

Fuente: Elaboración propia (2021).

La información recogida permitió determinar el comportamiento del rango de ventas durante el ejercicio económico del 2020, el $44.59 \%$ de encuestados ha presentado un 
rango estimado entre $\$ 0$ a $\$ 100.000$, el $22.51 \%$ de las empresas registran un rango de ventas de entre $\$ 300.001$ a $\$ 1.000 .000$, por otro lado el $14.23 \%$ de las empresas mencionan tener ventas entre $\$ 100.001$ a $\$ 300.000$, el $8,92 \%$ posee ventas de entre $\$ 1.000 .001$ a $\$ 2.000 .000$, el $5,31 \%$ de los encuestados señalan tener ventas de entre $\$ 2.000 .001-\$ 5.000 .000$ y finalmente un $4.46 \%$ cuentan con ventas mayores a $\$ 5.000 .000$. Existe un claro panorama de ventas que fluctúa de acuerdo al tipo de empresa y el bien o servicio que oferta, añadiéndole a ello los diferentes desafíos que han tenido que sobrellevar por la pandemia y las medidas de restricción emitidas.

De allí que es necesario el apoyo al sector productivo, entendiendo que en esta crisis hay actividades potencialmente ganadoras y perdedoras. En el primer grupo, tenemos productos agrícolas básicos, comercio electrónico, TICs, cuidados de salud y personales, procesamiento de alimentos, distribución y logística, accesorios y equipos médicos; mientras en el segundo grupo, tenemos al turismo, servicios de aviación y marítimos, construcción y bienes raíces, manufactura de productos no esenciales, servicios financieros, educación y combustibles, por ello es necesario promover el consumo, ya que este rubro corresponde a casi dos terceras partes del producto interno bruto del país. Para ello, una reducción temporal del impuesto al valor agregado u otros podría ser un buen incentivo al consumo Becerra, Flores y Cuadrado (2021). Si hay más consumo, se potenciará la base de contribución, de lo contrario no habrá impuestos que tributen las micro, pequeña y medianas empresas.

Figura 3. Distribución de productos y/o servicios a los clientes ante la presencia del COVID 19.

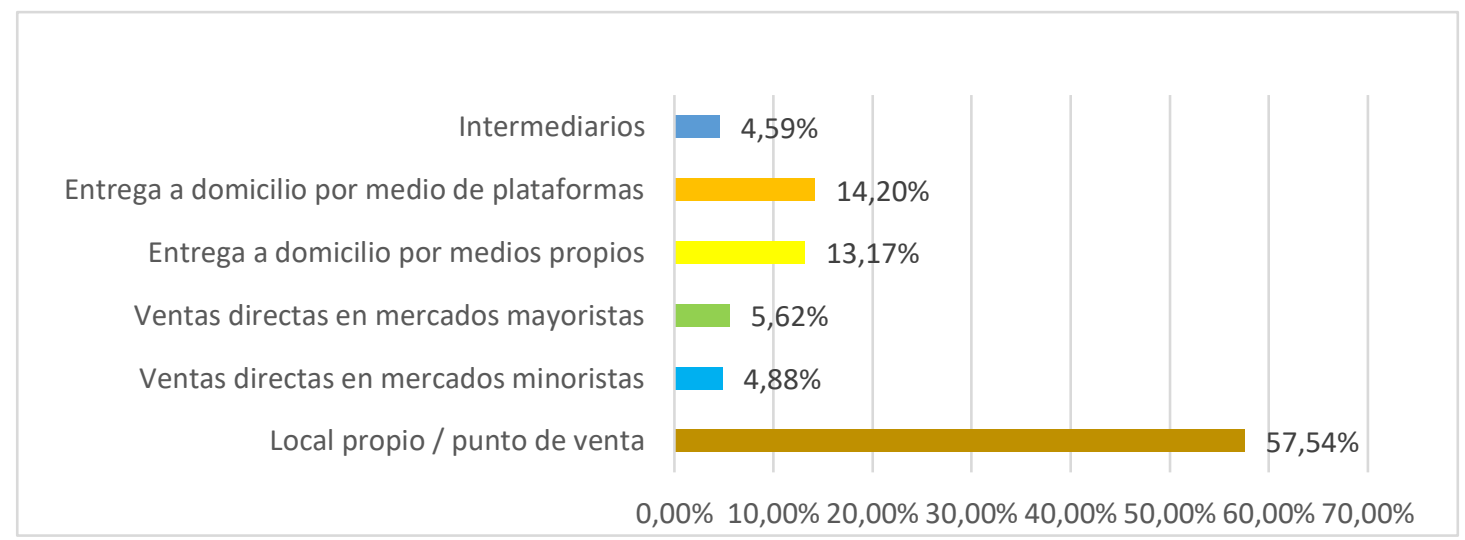

Fuente: Elaboración propia (2021).

El análisis indicó, según la figura $\mathrm{N}^{\circ} 3$, con respecto a la distribución de productos y/o servicios a los clientes ante la presencia del COVID 19, la tendencia muestra que un $57.54 \%$ usa un local propio para sus actividades productivas y comerciales, el $14.20 \%$ realiza la entrega a domicilio por medio de plataformas tecnológicas tales como los navegadores web (por ejemplo, Chrome, Safari, Internet Explorer), los sitios de redes sociales, como Facebook, Twitter, WhatsApp, así como las aplicaciones móviles Android y Apple (IOS). El $13.17 \%$ entrega a domicilio por cuenta propia y así también tienen un ingreso extraordinario por el envió. 
El servicio de entrega a domicilio permite que el consumidor adquiera productos sin salir de casa, por lo cual tiene que hacer una lista de lo que necesita con las mayores especificaciones posibles, sin contar con aplicaciones móviles para hacerlo, esta es una idea favorable para el consumidor, el 5.62\% por ventas directas a mayoristas, hoy muchas empresas buscan mayor eficiencia en sus ventas utilizando canales directos de distribución evitando las ventas por medio de mayoristas, el $4.88 \%$ por ventas directas en mercados minoristas, que son las realizadas por los comerciantes minoristas, es decir venden directamente a los consumidores finales. El comerciante minorista es, tal como su nombre indicó, el que vende al por menor o al detalle sus productos, y el $4.59 \%$ por intermediarios, o por personas y empresas que sirven como nexo para comercializar la disponibilidad de productos, bienes y servicios de unos productos y la persona que lo demanda, logrando ampliar el mercado brindando facilidades para los consumidores.

Figura 4. Importancia del diferimiento de pagos de deudas en las Mipymes.

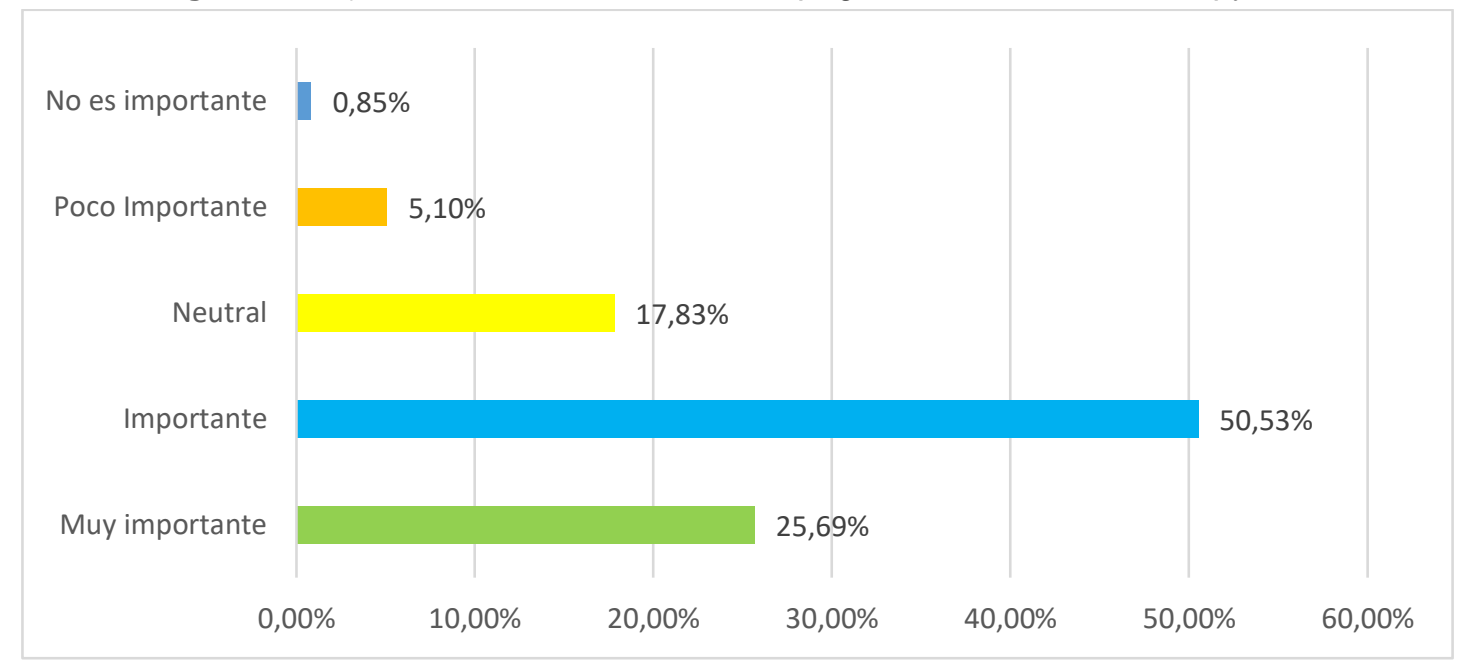

Fuente: Elaboración propia (2021).

Los resultados obtenidos de los cuestionarios aplicados a los actores empresariales establecen que el diferimiento de pagos de deudas es un factor determinante en la salud financiera de las Mipymes, el 50,53\% sostienen que fue importante esta medida dispuesta por el gobierno, en tanto que el 25,69\% afirman que fue muy importante, al unir estas tendencias tenemos el 76,22\% de ejecutivos empresariales, esta estrategia permitió oxigenar y aliviar a las micro, pequeñas y medianas empresas que no tuvieron ingresos estables, como los comerciantes de la calle, tiendas, almacenes, bazares, restaurantes, cafeterías que viven de las ventas diarias, por el confinamiento desde mediados de marzo hasta finales de junio del 2020, la Superintendencia de Bancos dispuso que, a nivel general los pagos y cuotas de capital e intereses por concepto de obligaciones financieras diferidas extraordinariamente, no causarán intereses moratorios, gastos, recargos ni multas durante el periodo o plazo acordado con el deudor, de allí que las instituciones financieras procedieron a diferir 2 o 3 cuotas, y extender el plazo de pago en 3 meses, para los microcréditos y los créditos productivos de pequeñas empresas que así lo requirieron. Así mismo el 17,83\% se mantuvo neutral, es decir que no estaban de acuerdo y en desacuerdo con el diferimiento de pagos por créditos otorgados por el Sector 
Financiero, el 5,10\% manifestaron que es poco importante, mientras que el 0,85\% sostuvieron que no es importante, toda vez que no consideraron este beneficio bajo nuevas condiciones porque a la final terminarían pagado sus intereses en un tiempo más prolongado, además que contaban con recursos que les permitió operar durante el confinamiento, por la presencia del COVID 19.

Figura 5. Costos adicionales, que ha incurrido la empresa para estar funcionando.

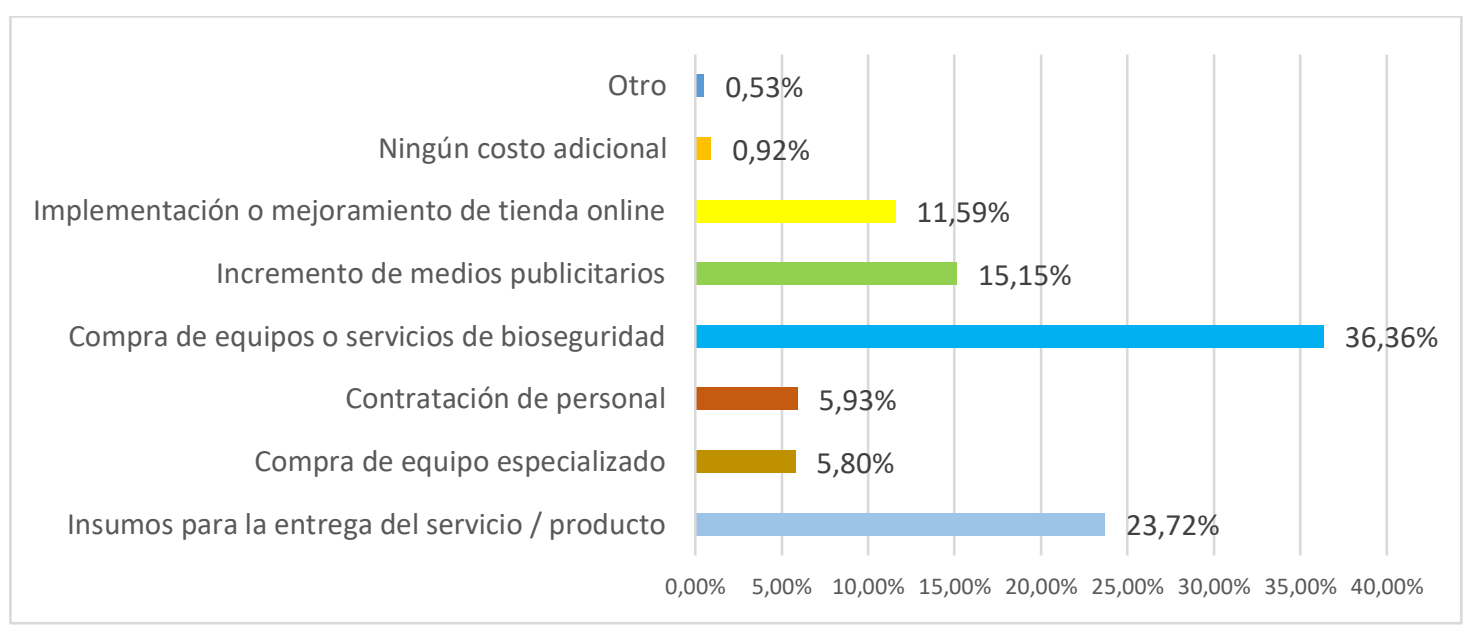

Fuente: Elaboración propia (2021).

Las opiniones emitidas en cuanto a los costos adicionales incurridos por las empresas para su funcionando señalan que el $36.36 \%$ de las empresas hicieron compras de equipos o servicios de bioseguridad para la protección de la salud tanto de empleadores y sus trabajadores, esta fue una inversión necesaria e inteligente, con el fin de reducir el riesgo de transmisión de COVID 19, el $23.72 \%$ en insumos para la entrega del producto o servicio, requeridos en los servicios de alimentación y las actividades de control de inventario, esto implica desde la solicitud de los insumos y/o productos a los proveedores, hasta la entrega de los mismos al supervisor de turno, los líderes de los servicios de alimentación o a los empleados a quienes se delegue, este costo aumentó debido al temor que las personas tenían de contagiarse, haciendo que disminuyeran las ventas por desconfianza, así mismo el $15.25 \%$ incrementó su presupuesto en medios publicitarios para mostrarse ante sus clientes potenciales, especialmente mediante el internet y la amplia gama de oportunidades que ofrece el mundo digital, plataformas y redes sociales que las empresas lo vieron como una oportunidad.

El 11,59\% se orientó a la implementación o mejoramiento de su tienda online, es decir tiendas virtuales o tiendas electrónicas, un tipo de comercio que usa las bondades de la tecnología y el comercio electrónico como herramientas esenciales para realizar sus transacciones a través de un sitio web o una aplicación conectada a Internet, en tanto que, el $5.93 \%$ tuvieron que invertir en la contratación de personal, principalmente empresas farmacéuticas o supermercados requirieron incrementar su personal, ya que dentro del caos estos dos sectores fueron los más demandados, el 5,80\% compró equipos especializados, insumos, dispositivos y equipos médicos para la emergencia por Covid- 
19, además de propiedad, planta y equipo a ser utilizado por la empresa para generar renta o ingresos, como puede ser el caso de una máquina o equipo de una empresa industrial, un teléfono celular, un computador entre otros, el $0.92 \%$ no tuvo ningún costo adicional y el $0.53 \%$ tuvieron otros costos.

\section{Análisis Créditos para las Mipymes en el Ecuador}

En esta crisis, la economía se ha paralizado durante varias semanas y la recuperación de la actividad se produce en un nuevo entorno mucho más incierto, en el que los procesos productivos y los patrones de consumo se ven afectados por las medidas de seguridad sanitaria, y en el que muchas empresas y puestos de trabajo no habrán logrado sobrevivir.

Para aliviar las cargas financieras el gobierno tuvo que tomar las siguientes acciones; con respecto al Instituto Ecuatoriano de Seguridad Social -IESS, se aplazó por 90 días el pago de los aportes de abril, mayo y junio de los afiliados voluntarios y sin relación de dependencia. Esto se suma al anuncio del diferimiento a 6 meses del pago del Impuesto a la Renta de abril, mayo y junio de los sectores turísticos, exportadores y de pequeños contribuyentes.

Por su parte la BanEcuador y la Corporación Financiera Nacional - CFN, postergaron los pagos de marzo, abril y mayo de la siguiente manera; los intereses no cobrados se repartieron en 12 meses a partir de junio y el capital se dividió hasta el final del periodo del crédito. Así mismo el Banco del Instituto Ecuatoriano de Seguridad Social-BIESS, emitió la resolución para los clientes del BIESS que se encontraban en mora se beneficiaron de una reestructuración y refinanciamiento de sus préstamos hipotecarios hasta 18 meses de gracia y 30 años plazo. Por otro lado, el Banco de Desarrollo del Ecuador- BEDE, estableció para los pequeños y medianos gobiernos seccionales que son usuarios, la posibilidad de solicitar una reestructuración de sus deudas con un periodo de gracia o una ampliación de plazo de acuerdo con la realidad local.

De igual forma las cooperativas de ahorro y crédito, que administran recursos de la Corporación Nacional de Finanzas Populares y Solidarias (CONAFIPS) pudieron reprogramar las cuotas de abril y mayo y refinanciaron operaciones de sus clientes finales pudiendo acceder a créditos de 12 meses en la Corporación. Por otro lado, los Bancos aplazaron hasta por 60 días sin recargos el cobro de cuotas de crédito personales, microcréditos y pequeñas empresas. También refinanciaron las deudas de acuerdo con las necesidades particulares, establecieron también créditos de contingencia a largo plazo para la recuperación productiva de otros sectores afectados, para el caso concreto de los trabajadores de cuenta propia se elaboró un plan especial.

En concordia con lo expuesto, los Bancos y Cooperativas ofrecieron beneficios para aliviar la presión de las obligaciones crediticias de sus clientes, en un escenario de menor liquidez en las Mipymes, por la emergencia del COVID-19. No obstante de 24 bancos privados que operan en Ecuador, los 16 que son parte de la Asociación de Bancos Privados del Ecuador - (ASOBANCA), con resolución de fecha 16 de marzo del 2020, aplazaron hasta por 60 días el cobro de las cuotas de los préstamos de tres tipos de 
beneficiarios, en el primer grupo están los clientes con créditos personales de consumo; por ejemplo, para adquirir autos, pagar un viaje, amoblar la casa, entre otros, en el segundo lugar están los microcréditos; es decir, aquellos que se entregan a personas naturales o jurídicas con ventas de hasta USD \$ 100.000; y, en el tercer lugar, los préstamos a empresas pequeñas. En este sentido para estos segmentos también se refinanciaron las condiciones de las tablas de amortización. Es de indicar que no fue necesario que la Junta de Política y Regulación Monetaria emita una resolución para implementar estas decisiones, que se aplicaron de manera inmediata.

Con respecto a las deudas con tarjetas de crédito, préstamos hipotecarios y las operaciones crediticias de empresas medianas y grandes no recibieron el beneficio de aplazamiento de cuotas. No obstante, de esto, cada banco evaluó la situación del acreedor y decidió si ofrecer el refinanciamiento. Otro aspecto que es necesario señalar es que algunos bancos decidieron incluir a las obligaciones con tarjetas de crédito, pero eso es parte de la estrategia de cada institución financiera, por ello cada banco ofreció facilidades en la medida en que le fueron posibles, así el Banco Guayaquil, por ejemplo, incluyó las deudas con tarjeta de crédito en las dos opciones de financiamiento.

Por la diversidad de opciones presentadas por el sistema financiero nacional cada cliente debía acercarse a su institución financiera y comprobar las afectaciones y manifestar su consentimiento para acceder a ellas.

Por otra parte, la Unión de Cooperativas del Sur (UCACSUR), que agrupa a 15 cooperativas que representan el $30 \%$ de los activos de la economía popular y solidaria, también dio una gracia hasta por 90 días en las cuotas, para tal fin cada cooperativa analizó qué tipo de crédito y desde cuándo aplicó, favoreciendo a los socios que generalmente son microempresarios que generan sus ingresos con el trabajo diario y no pudieron tener los fondos suficientes para cubrir sus obligaciones.

Como puede advertirse, las instituciones financieras privadas trabajaron, durante el estado de emergencia en ventanillas, pero instaron a los clientes a preferir el uso de medios digitales o de la banca telefónica. En este sentido los bancos, operaron con medidas como teletrabajo, desinfección en cada puesto y dispensarios médicos para sus trabajadores. Durante el estado de emergencia de la información recogida se pudo determinar un crecimiento significativo de los servicios de banca virtual, es decir un crecimiento de transacciones. Ante la emergencia nacional por el COVID 19, las cooperativas y bancos emprendieron planes con beneficios para clientes. Estas entidades, además, aplicaron programas para aumentar los controles sanitarios en la matriz, sucursales y agencias bancarias de todo el país.

En consecuencia, en el Ecuador existen varias vías de acceso a un crédito, ya sean públicas o privadas. Los préstamos oscilan de mínimos de $\$ 500$ a $\$ 2.000$ a máximos desde \$50.000 hasta \$25 millones, enfocados para emprendedores, microempresarios y empresarios. De allí que los microcréditos, van dirigidos para quienes deseen incrementar el volumen de los negocios de los trabajadores autónomos o para impulsar un modelo de comercio social. Por ejemplo, BanEcuador ofrece créditos que van desde $\$ 500$ hasta un 
total de 150 remuneraciones mensuales unificadas (RMU), esto es, \$57.900. Así mismo tiene otros programas como: Crédito Joven, Gran Minga Agropecuaria y Banco del Pueblo, en este último su máximo es de $\$ 15.000$ y va enfocado a apoyar a las asociaciones, organizaciones comunitarias, emprendedores, de las zonas rurales y urbanas, las tasas de interés que maneja la institución van desde el 9,76\% al 11\%.

En tal sentido, la Corporación Financiera Nacional (CFN), a través, del Fondo Nacional de Garantías (FNG) da créditos para emprendedores hasta $\$ 100.000$, no hay una cantidad mínima establecida. La persona puede solicitar desde cualquier monto, de esta manera se brinda oportunidades de crecimiento a jóvenes, emprendedores y pequeños empresarios. Esta alternativa de crédito funciona con Banco del Pacífico, Banco General Rumiñahui, Banco Amazonas, Banco Comercial de Manabí, Banco Procredit, Banco Finca, Cooperativa de Ahorro y Crédito Alianza del Valle, Cooperativa de Ahorro y Crédito Andalucía, Del Bank y el Banco del Litoral.

Para quienes tienen pequeñas y medianas empresas, por lo general, sus apegos en líneas de créditos son más elevados con otro tipo de plazos, periodos de gracia y por supuesto, tasa de interés. Por su parte, la Corporación Financiera Nacional (CFN), otorga financiamiento desde $\$ 50.000$ hasta $\$ 25$ millones. Adicionalmente, $\$ 50$ millones para grandes grupos económicos, para ello es necesario el estado de situación financiera, estado de resultados y flujo de caja proyectado, además dar información de su plan de negocios que incluya: Plan de inversiones, esquema de financiamiento, oferta, demanda, precios, costos, entre otros. Igualmente, las garantías son de tipo hipotecario (terrenos, edificios, galpones) o prendario (vehículos, maquinarias, equipos, entre otras), el porcentaje de cobertura requerido es de al menos $125 \%$.

En cuanto a las tasas de interés, estas van en función al segmento del crédito al cual pertenece el cliente, plazo y destino de la operación, por ejemplo, las tasas de interés para los créditos: Corporativo 7.50\%, Empresarial 8.25\% y Pyme 9.75\%, la tasa de interés para el sector Microcrédito es del $24 \%$ si se trata de niveles de ventas menores de $\$ 100.000$; y del $11.23 \%$ nominal si el negocio vende entre $\$ 100.000$ a un millón de dólares. Estas tasas generalmente son reajustables en base a la TPR (Tasa Pasiva Referencial) del Banco Central del Ecuador, varias son las opciones para acceder a un crédito, sea desde el lado público o privado, todo dependerá para qué se desea y si va a cubrir la necesidad de la Mipyme.

Según, Becerra y Cuadrado (2020) para facilitar los pagos de los créditos es importante poner a disposición de la ciudadanía mecanismos que garanticen la recuperación de la cartera, apoyando al crecimiento sostenido del patrimonio y la sobrevivencia en el largo plazo de las instituciones financieras, disminuyendo de esta forma el riesgo financiero.

\section{Conclusiones}

A continuación, se exponen las principales conclusiones, integrando los resultados de los cuestionarios, y la técnica de la observación: 
- La información recogida en los gráficos $\mathrm{N}^{\circ} 1,2$ y 3 respectivamente, sostiene que operan parcialmente el $68.15 \%$, como consecuencia de la caída en los ingresos, por la disminución de las ventas, producida por la pandemia del COVID 19, los empresarios opinan que promover el consumo es fundamental para la reactivación de las actividades comerciales que ellos viven del ingreso diario, esto se evidencia conforme se refleja en el grafico $\mathrm{N}^{\circ} 2$, que corresponden al grupo de microempresarios y emprendedores cuyas ventas son menores a los $\$ 100.000,00$, con el 44,59\%, así mismo la distribución de los productos y/o servicios se realizan en un porcentaje del $57,54 \%$ en el local propio o punto de venta.

- El comercio electrónico a través de varias plataformas y la entrega a domicilio con un $27.37 \%$ fueron parte de las innovaciones en los negocios que devinieron de la pandemia.

- El análisis de los gráficos $\mathrm{N}^{\circ} 4$ y 5 con respecto a la importancia del diferimiento de pagos de deudas que incidieron en las micro, pequeñas y medianas empresas, el 76,22\% sostienen que fue transcendental esta medida dispuesta por la Junta de Política y de Regulación Monetaria, esto permitió tranquilizar a las micro, pequeñas y medianas empresas que no tuvieron ingresos sólidos, para atender los pagos de capital e de intereses, hasta por dos o tres meses, esto permitió conforme grafico $\mathrm{N}^{\circ} 5$, que las empresas hayan incurrido a la compra en una buena parte de equipos o insumos de bioseguridad, en el 36.36\% para el resguardo y protección de la salud tanto de empresarios y sus colaboradores, para menguar el riesgo del contagio de coronavirus.

- Ha pasado poco más de un año y medio desde que la pandemia inició su brutal golpe sobre la salud de cientos de ecuatorianos y particularmente de la zona 6, y sobre todo de la economía. La respuesta de las autoridades para atender la emergencia en ambos casos, con la ayuda del sector privado, la academia y la sociedad civil, ha sido oportuna. Actualmente el gobierno viene trabajando en forma conjunta y solidaria, por ello consideramos que podremos superar la crisis de salud que enfrentamos. Ahora bien, no nos podemos quedarnos en esta etapa, debemos comenzar a prepararnos para superar la crisis económica en que hemos caído por responder a la crisis de salud. De allí nace el gran reto que nos espera en materia de reactivación económica, es importante tener presente que la superación de este reto solo se alcanzará de manera satisfactoria mediante la vacunación de la población llegando a la inmunidad de rebaño y la tan ansiada reactivación del tejido empresarial.

- Los datos contenidos en la información recogida permiten determinar que los impactos repentinos de la pandemia en los negocios, teniendo que acoplarse a la situación del momento, algunos negocios que sí lograron quedarse de pie tomaron decisiones que llevaron a involucrarse con la tecnología. La acción de quedarse en casa dio como consecuencia la disminución en las ventas para los locales que tenían un puesto estable en el mercado esto ante el temor de contagio por COVID 19. 
- Pocas empresas contrataron personal, pero algunas tuvieron que despedir a sus colaboradores. El mercado creció para los negocios de primera necesidad, comida y farmacias, negocios como venta de ropa o accesorios fueron afectados.

- Los resultados indicaron que los créditos son los mejores instrumentos financieros para adquirir productos y servicios y pagarlos en plazos cómodos. Los créditos permiten que las micro, pequeñas y medianas empresas, tengan liquidez, para cubrir sus obligaciones con proveedores, trabajadores, administración tributaria, Instituto Ecuatoriano de Seguridad Social, es importante que las empresas paguen sus préstamos sin morosidad por sus operaciones para garantizar su permanencia en el mercado. Es ahí donde la banca tiene que estar a la altura de las circunstancias, garantizando la liquidez y la financiación que necesitan las empresas.

- Finalmente se sostiene la importancia del sector financiero y la diversidad de los servicios que atienden a las particularidades de las Mipymes, sumada a la pronta acción gubermental y la aceptación por parte de las entidades financieras, constituyendo elementos esenciales para la reactivación económica y mitigar los efectos negativos de la crisis.

\section{Referencias bibliográficas}

Arias, F. (2016). El Proyecto de Investigación: Introducción a la metodología científica. ( $7^{a}$ Edición), Caracas - Venezuela. Editorial El pasillo, C.A.

Asamblea Constituyente. (2008). Constitución de la República del Ecuador. Montecristi: Asamblea Constituyente, Gaceta oficial No 449 del 20 de octubre del 2008.

Banco Central del Ecuador (2021), recuperado de: https://www.gob.ec/bce

Becerra, E. \& Cuadrado, G. (2020). El microcrédito productivo como dinamizador de la economía campesina en la región del Austro. Visionario Digital, 4(4), 6-31.

Becerra, E., Flores, M. E., \& Cuadrado, G. (2021). La fiscalidad en las Mipymes de la región del Austro, en el contexto de la pandemia del COVID-19. AlfaPublicaciones, 3(3), 98-119.

Boholasvsky, J. P. (2020). Covid-19, instituciones financieras internacionales y continuidad de las políticas androcéntricas en América Latina. Scielo. Obtenido de https://www.scielo.br/scielo.php?script=sci_arttext\&pid=S0104026X2020000200201\&lng=es\&nrm=iso\&tlng=es

Casero, M., Crespo, C., Mateo, M., \& Vidal, J. (2020). revistasice.com. Obtenido de: revistasice.com: http://www.revistasice.com/index.php/BICE/article/view/7176/7179 
Centro de Desarrollo de la OCDE. (2020). Impacto financiero del covid-19 en ecuador: desafios y respuestas, obtenido de: https://www.oecd.org/dev/Impactofinanciero-COVID-19-Ecuador.pdf

Hernández, S., Fernández, C., \& Baptista, L. (2016). Metodología de la Investigación. México: Mc Graw Hill Educación, 6ta. Edición.

INEN. (2020). SERVICIO ECUATORIANO DE NORMALIZACION. Obtenido de https://www.normalizacion.gob.ec/mipymes-y-organizaciones-de-economiapopular-y-solidaria-son-una-pieza-clave-para-la-economia-del-pais.

La Comisión Económica para América Latina - CEPAL (2021), Obtenido de: cepal.org: https://www.cepal.org/es/comunicados/covid-19-tendra-graves-efectos-laeconomia-mundial-impactara-paises-america-latina

Ley Orgánica de apoyo humanitario (2020). Gaceta oficial $\mathrm{N}^{\circ} 229$, del 22 de junio del 2020

Lozada, M. (2020). La Función Financiera de la Empresa. Ecofinanzas, recuperado de: https://asesoriaslozada.blogspot.com/2020/04/la-funcion-financiera-de-laempresa.html

OCDE. (2020). oecd.org. Obtenido de oecd.org: https://www.oecd.org/dev/Impactofinanciero-COVID-19-Ecuador.pdf

Yuni, J. y Urbano, C. (2006). Técnicas para investigar, segunda edición. Buenos Aires: Brujas.

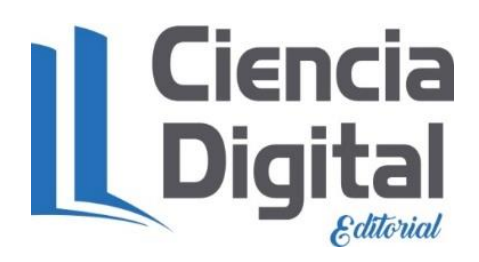




\section{PARA CITAR EL ARTÍCULO INDEXADO.}

Becerra Molina, E., Cuadrado Sánchez, G., \& Flores Flores, M. E. (2021). Medidas financieras en el entorno de los negocios, para minimizar los efectos de la pandemia COVID-19. ConcienciaDigital, 211-231. https://doi.org/10.33262/concienciadigital.v4i3.1800

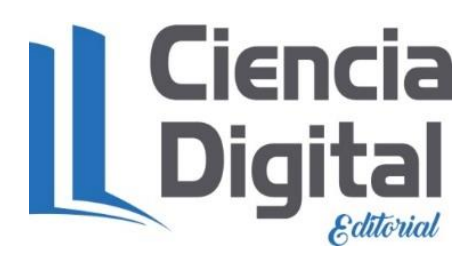

El artículo que se publica es de exclusiva responsabilidad de los autores y no necesariamente reflejan el pensamiento de la Revista Conciencia Digital.

El artículo queda en propiedad de la revista y, por tanto, su publicación parcial y/o total en otro medio tiene que ser autorizado por el director de la Revista Conciencia Digital.

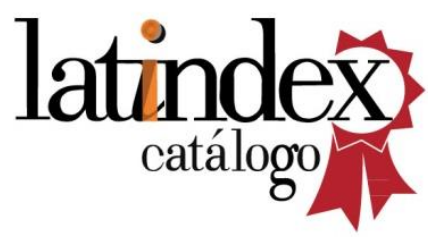

